\title{
MODEL BIMBINGAN KELOMPOK BERBASIS NILAI BUDAYA BUTON UNTUK MENINGKATKAN KECERDASAN INTERPERSONAL SISWA
}

\author{
oleh: \\ SAMSAIFIL \\ Dosen Bimbingan dan Konseling FKIPUHO \\ Email: samsaifil.017@gmail.com
}

\begin{abstract}
ABSTRAK
Tujuan penelitian ini (1) Memperoleh gambaran pelaksanaan bimbingan kelompok di SMA Negeri Bau-bau. (2) Memperoleh gambaran kecerdasan interpersonal siswa di SMA Negeri 5 Bau-bau. (3) Tersusunnya model bimbingan kelompok berbasis nilainilai budaya Buton untuk meningkatkan kecerdasan interpersonal siswa SMA Negeri Bau-bau. (4) Mengetahui efektifitas pelaksanaan bimbingan kelompok berbasis nilainilai budaya Buton untuk meningkatkan kecerdasan interpersonal siswa. Penelitian ini menggunakan Metode Research and Development (R\&D). Bimbingan kelompok sudah dilaksanakan, namun belum menginternalisasikan nilai-nilai budaya Buton, sehingga belum efektif untuk meningkatkan kecerdasan interpersonal siswa. Model bimbingan kelompok berbasis nilai-nilai budaya Buton untuk meningkatkan kecerdasan interpersonal siswa terdiri dari: (1) rational, (2) the vision and mission, (3) objectives, (4) the content of counseling, (5) support systems (6) stages of the model guidance based group cultural values Buton, (7) the material, (8) games. (1) rasional, (2) visi dan misi, (3) tujuan, (4) isi bimbingan konseling, (5) dukungan sistem (6) tahap-tahap model bimbingan kelompok berbasis nilai-nilai budaya Buton, (7) materi, (8) permainan. Hasil uji pre-test dan post-test setelah uji lapangan, mengalami peningkatan sebesar $11,77 \%$ dan Hasil uji statistik perhitungan wilcoxon juga menunjukkan asymp.sig. (2-tailed) $0,012<0,05$ sehingga dapat disimpulkan bahwa bimbingan kelompok berbasis nilai-nilai budaya Buton terbukti efektif untuk meningkatkan kecerdasan interperonal siswa.
\end{abstract}

\section{Kata Kunci: Bimbingan Kelompok, Nilai-nilai Budaya Buton, Kecerdasan Interpersonal}

\section{ABSTRACT}

The purpose of this study (1) Obtains a description of the implementation of group guidance in the SMA Negeri Bau-bau. (2) Obtaining a description of student interpersonal intelligence in the SMA Negeri 5 Bau-bau. (3) Establishment of the model of group guidance based cultural values Buton to improve students' interpersonal intelligence SMA Bau-bau.(4) Knowing the effectiveness of group guidance based on the cultural values of Buton to improve students' interpersonal intelligence. This study uses a method of Research and Development $(R \& D)$. Group guidance was made, but not yet internalized cultural values of Buton. So it is not effective to improve students' interpersonal intelligence. Model of group guidance-based cultural values Buton to improve students' interpersonal intelligence consists of (1) rational, (2) the vision and mission, (3) objectives, (4) the content of counseling, (5) support systems (6) stages of 
the model group guidance based cultural values Buton, (7) the material, (8) games. The result of the pre-test and post-test after field tests, an increase of $11.77 \%$, and statistical calculations Wilcoxon test results also show Asymp.Sig. (2-tailed) $0.012<0.05$ so it can be concluded that of the group guidance based cultural values of Buton proven effective to improve student's interpersonal intelligence.

Keywords: Group guidance, Buton cultural values, intelligence, interpersonal.

\section{PENDAHULUAN}

Bimbingan kelompok sangat perlu untuk diterapkan dalam dunia pendidikan. Melalui layanan bimbingan kelompok, siswa memperoleh kesempatan mengembangkan sikapsikap positif seperti toleransi, kerjasama, tanggung jawab dan empati. Romlah 2006 menjelaskan bahwa bimbingan kelompok sebagai bantuan terhadap siswa yang dilaksanakan dalam situasi kelompok dan bertujuan untuk mencegah timbulnya masalah dan pengembangan potensi yang ada pada siswa

Layanan bimbingan kelompok sangat bermanfaat bagi siswa karena melalui dinamika dan interaksi dengan anggota-anggota kelompok, siswa dapat memenuhi beberapa kebutuhan psikologis seperti kebutuhan menyesuaikan diri dengan teman sebaya, kebutuhan untuk saling berbagi pengalaman, kebutuhan untuk menemukan nilai-nilai yang ada di lingkungannya dan menjadikan nilainilai tersebut sebagai pedoman, serta kebutuhan bagi kehidupan, penyelesaian masalah. Dengan demikian dapat dikatakan bahwa layanan bimbingan kelompok mampu membantu siswa membangun hubungan interpersonal yang baik.

Nilai-nilai budaya lokal hendaknya memperoleh tempat dalam pendidikan, baik itu dalam proses pembelajaran maupun dalam layanan bimbingan dan konseling. Hal ini senada dengan yang diungkapkan Tilaar 2004 bahwa dalam upaya memperkuat jatidiri bangsa dapat dilakukan melalui internalisasi nilainilai budaya dalam pendidikan. Layanan bimbingan kelompok yang berbasis budaya lokal penting dalam memberi peluang pada siswa untuk mengapresiasi masalah-masalah dan kemungkinan pemecahannya menurut landasan nilai-nilai yang dianutnya.

Memperhatikan nilai-nilai kebudayaan dalam menyelenggarakan layanan bimbingan kelompok menjadi perlu, mengingat yang menjadi objek layanan tersebut adalah siswa sebagai individu yang sedang berkembang (becoming), dan salah satu hal yang mempengaruhi perkembangan individu adalah kebudayaan dimana individu tersebut berasal. Hurlock 2009. Menyatakan bahwa perkembangan dipengaruhi oleh budaya.

Kecerdasan interpersonal merupakan hal yang sangat penting bagi kehidupan individu sebab dengan kecerdasan interpersonal yang tinggi individu tidak terlalu mengalami kesulitan dalam membina hubungan dengan orang lain, baik dengan orang yang baru dikenal maupun dengan teman lama.

Berdasarkan hasil wawancara awal yang dilakukan peneliti terhadap Siswa dan guru bimbingan dan konseling di tiga SMA Negeri Bau-bau 
yaitu SMA Negeri 2 Bau-bau, SMA Negeri 4 Bau-bau, dan SMA Negeri 5 Bau-bau, ditemukan masih terjadinya tawuran antar kelompok, saling mengancam, dan terjadi komunikasi yang kurang baik seperti ejekan verbal antar sesama siswa, kurang berempati, sehingga menjadi permasalahan yang berujung pada penanganan oleh guru bimbingan dan konseling. Selain itu, ditemukan perilaku siswa yang menggambarkan gangguan dalam berelasi di lingkungan sekolah, seperti berbicara kasar pada teman, kurangnya kesediaan untuk bekerjasama antara sesama siswa, kurangnya rasa percaya diri dalam bergaul dan berkomunikasi.

Gejala-gejala yang ditemukan dalam wawancara mengindikasikan kurangnya kecerdasn interpersonal. Safaria 2005 mengatakan, kecerdasan interpersonal atau bisa juga dikatakan kecerdasan sosial diartikan sebagai kemampuan dan keterampilan seseorang dalam menciptakan relasi sosialnya sehingga kedua belah pihak berada dalam situasi menang-menang atau saling menguntungkan.

Berdasarkan fenomena di atas maka diperlukan upaya meningkatkan kecerdasan interpersonal siswa untuk meminimalisir timbulnya masalahmasalah berupa perilaku-perilaku maladaptif yang memiliki potensi menjadi problem kehidupan yang berkepanjangan baik bagi dirinya maupun lingkungan di sekitarnya. Karena bimbingan kelompok yang dilaksanakan di SMA Negeri Bau-bau masih menggunakan bimbingan kelompok yang bersifat umum tampa memasukan nilai-nilai budaya Buton, maka perlu untuk menginternalisasikan nilai-nilai budaya Buton seperti 1). pobhinci-bhinciki Kuli "Pandai Memahami Perasaan orang lain, (2).
Pomae-maeaka bermakna saling menghormati antara sesama anggota masyarakat, (3). Pomaa-maasiaka bermakna senantiasa hidup saling peduli dan saling menyayangi (4). Popia-piara bermakna saling memelihara kedamaian, ketentraman. (5). Poangka-angkataka bermakna hidup bermanfaat dengan saling mengangkat derajat antara sesama anggota masyarakat. (6) Bholimo karo sumanamo lipu, bermakna mementingkan kepentingan sosial diatas kepentingan pribadi dan (7) Adatina pogau te adatina pomingku bermakna etika berbicara dan etika dalam bersikap dalam hubungan sosial.

Masalah yang akan diteliti adalah Bagaimanakah pelaksanaan bimbingan kelompok di SMA Negeri Bau-bau? Bagaimanakah tingkat kecerdasan interpersonal siswa di SMA Negeri Bau-bau? Bagaimanakah model bimbingan kelompok berbasis nilai-nilai budaya Buton untuk meningkatkan kecerdasan interpersonal siswa SMA Negeri Bau-bau? Bagaimanakah tingkat keefektifan layanan bimbingan kelompok berbasis nilai budaya Buton untuk meningkatkan kecerdasan interpersonal siswa SMA Negeri Baubau?

Secara rinci tujuan penelitian ini adalah sebagai berikut : Memperoleh gambaran pelaksanaan bimbingan kelompok pada SMA Negeri Bau-bau. Memperoleh gambaran tingkat kecerdasan interpersonal siswa SMA Negeri Bau-bau. Tersusunnya model bimbingan kelompok berbasis nilai-nilai budaya Buton untuk meningkatkan kecerdasan interpersonal siswa SMA Negeri Bau-bau. Mengetahui efektifitas pelaksanaan bimbingan kelompok berbasis nilai-nilai budaya Buton untuk 
meningkatkan kecerdasan interpersonal siswa di SMA Negeri Bau-bau

\section{METODE PENELITIAN}

Metode yang digunakan dalam penelitian ini adalah metode penelitian dan pengembangan (Research \& Development) Borg and Gall dalamSamsudi, 2009. Dengan modifikasi hanya melalui 6 (enam) tahapan yakni tahap persiapan pengembangan model, tahap perumusan model hipotetik, tahap kelayajan model hipotetik, tahap perbaikan model hipotetik, tahap uji efektifitas, dan tahap akhir.

Uji coba dilakukan untuk menguji apakah model yang dikembangkan telah memenuhi kriteria sebagai model bimbingan kelompok yang efektif digunakan di sekolah. Uji ahli dilakukan dengan melibatkan 4 orang pakar dua orang pakar bimbingan dan konseling dan dua orang pakar budaya Buton untuk memvalidasi model hipotetik secara akademik. Uji praktisi dilakukan dengan melibatkan 9 orang praktisi bimbingan dan konseling untuk memvalidasi model hipotetik agar menjadi sebuah model yang praktis

Subyek uji coba dalam penelitian ini sebanyak 8 siswa yang ditentukan dengan teknik porpusive sampling, atau sampel bertujuan. Menurut Arikunto 2005. purposive sampling dilakukan dengan cara mengambil subjek bukan didasarkan atas random atau daerah tetapi didasarkan atas adanya tujuan tertentu. Peneliti mengambil sampel penelitian dari siswa SMA Negeri 5 Bau-bau. Penentuan sampel didasarkan dari hasil perolehan instrument skala psikologis yang merupakan pretest atau evaluasi awal yang diberikan kepada siswa SMA Negeri 5 Bau-bau yang bertujuan untuk mengetahui perolehan hasil tingkat kecerdasan interpersonal siswa. Subyek uji coba model sebanyak 8 orang siswa dengan tingkat kecerdasan interpersonal yang heterogen yaitu : tinggi, sedang, kurang dan rendah. Siswa-siswa tersebut akan diberikan layanan bimbingan kelompok berbasis nilai-nilai budaya Buton

Jenis data yang digunakan dalam penelitian pengembangan ini adalah data kualitatif dan data kuantitatif. Data kualitatif diperoleh dari hasil wawancara, observasi, serta lembar validasi ahli dan lembar validasi praktisi. Data kuantitatif diperoleh dari skala psikologis kecerdasan interpersonal yang diberikan kepada siswa. Untuk menganalisis keefektifan model bimbingan kelompok berbasis nilai-nilai budaya Buton untuk meningkatkan kecerdasan interpersonal siswa, desain yang akan digunakan oleh peneliti adalah pre-experimental design: one group pretest-posttest design. Pada desain ini terdapat evaluasi awal sebelum diberi treatment dan evaluasi akhir setelah diberi treatment. Treatment yang dimaksud adalah bimbingan kelompok berbasis nilai-nilai budaya Buton. Desain ini digambarkan sebagai berikut:

Tabel 1. Desain Pre-Experimental

\begin{tabular}{ccc}
\hline $\begin{array}{l}\text { Evaluasi } \\
\text { Awal }\end{array}$ & $\begin{array}{l}\text { Variabel } \\
\text { Bebas }\end{array}$ & $\begin{array}{l}\text { Evaluasi } \\
\text { Akhir }\end{array}$ \\
\hline $\mathrm{Y} 1$ & $\mathrm{X}$ & $\mathrm{Y} 2$ \\
\hline
\end{tabular}

Keterangan :

$\mathrm{Y}_{1}$ : Nilai pre-test (sebelum diberi bimbingan kelompok dengan teknik modeling )

$\mathrm{Y}_{2}$ : Nilai post-test (setelah diberi bimbingan kelompok dengan teknik modeling )

$\mathrm{X}$ : Treatment yang dilakukan

Untuk pengujian hipotesis
dalam penelitian ini, peneliti 
membandingkan tingkat kecerdasan emosional siswa sebelum dan sesudah diberikan perlakuan menggunakan rumus uji wilcoxon dengan menggunakan bantuan perangkat lunak (software) SPSS 20.00 for Windows. Jika hasil uji menunjukkan hasil yang signifikan, maka model bimbingan kelompok berbasis nilai-nilai budaya Buton efektif untuk meningkatkan kecerdasan interpersonal siswa.

\section{HASIL DAN PEMBAHASAN}

Hasil penelitian menunjukan pelaksanaan bimbingan kelompok di SMA Negeri Bau-bau telah dilaksanakan oleh guru bimbingan dan konseling sesuai dengan tahapan bimbingan kolompok yang umum yaitu tahap pembukaan, peralihan, kegiatan dan pengakhiran. Namun belum menggunakan pendekatan budaya setempat dan belum membahas topiktopik yang berkaitan dengan kecerdasan interpersonal secara spesifik. Penyusunan program bimbingan konseling di SMA Negeri Bau-bau, sudah silakukan diawali dengan kegiatan need asessment, dengan menggunakan daftar cek masalah (DCM) dan mengevaluasi program program bimbingan konseling sebelumnya, namun belum melakukan asesmen lingkungan seperti

Tabel 1. Hasil Pengukuran Skala Psikologis Kecerdasan Interpersonal Siswa di SMA Negeri 5 Bau-bau Sebelum Uji Coba Model

\begin{tabular}{|c|c|c|c|c|c|c|c|}
\hline \multirow{2}{*}{ No. } & \multirow{2}{*}{ Indikator } & \multirow{2}{*}{ Frekuensi \& \% } & \multicolumn{4}{|c|}{ Kriteria } & \multirow{2}{*}{$\sum$} \\
\hline & & & $\mathbf{T}$ & $\mathbf{S}$ & $\mathbf{K}$ & $\mathbf{R}$ & \\
\hline \multirow[t]{2}{*}{1} & Sikap empati & Frekuensi & 73 & 66 & 4 & 0 & 143 \\
\hline & & $\%$ & 51 & 46,2 & 2,8 & 0 & $100 \%$ \\
\hline \multirow[t]{2}{*}{2} & Sikap prososial & Frekuensi & 56 & 80 & 7 & 0 & 143 \\
\hline & & $\%$ & 39,2 & 55,9 & 4,9 & 0 & $100 \%$ \\
\hline 3 & Percaya Diri & Frekuensi & 55 & 83 & 5 & 0 & 143 \\
\hline
\end{tabular}

menanyakan pada orang tua siswa tentang keinginan anak, menanyakan pada masyarakat di sekitar sekolah, penjaga kantin, dan pihak lain yang dianggap perlu. Waktu atau jadwal BK di SMA Negeri Bau-bau sudah dihapuskan atau ditiadakan, pertimbangannya jadwal BK dimanfaatkan untuk memenuhi kebutuhan guru matapelajaran (mapel) sebagai syarat sertifikasi, sehingga untuk melaksanakan bimbingan kelompok harus mencari waktu lain diluar jam pelajaran. Tetapi kalau guru BK mengadakan kegiatan bimbingan kelompok bisa memanggil siswa yang bersangkutan. Meskipun demikian layanan bimbingan kelompok masih tetap terlaksana. sarana yang dimiliki sudah cukup memadai, ada ruangan untuk kantor guru bimbingan dan konseling, ada ruang khusus konseling perorangan dan mengenai ruang khusus untuk pelaksanaan layanan yang bersifat kelompok termasuk layanan bimbingan kelompok belum tersedia secara memadai namun biasanya dilakukan di ruang Guru bimbingan dan konseling, di ruang pramuka dan di dalam kelas, disesuaikan dengan kebutuhan pelaksanaan bimbingan kelompok. 


\begin{tabular}{llllllll}
\hline & & $\%$ & 38,5 & 58 & 3,5 & 0 & $100 \%$ \\
\hline 4 & $\begin{array}{l}\text { Pemahaman situasi sosial } \\
\text { dan etika sosial }\end{array}$ & Frekuensi & 80 & 58 & 3 & 2 & 143 \\
\cline { 3 - 7 } & $\%$ & 55,9 & 40,6 & 2,1 & 1,4 & $100 \%$ \\
\hline 5 & $\begin{array}{l}\text { Keterampilan } \\
\text { memecahkan masalah }\end{array}$ & Frekuensi & 41 & 88 & 14 & 0 & 143 \\
\cline { 2 - 7 } & $\%$ & 28,7 & 61,5 & 9,79 & 0 & $100 \%$ \\
\hline 6 & Komunikasi efektif & Frekuensi & 41 & 89 & 11 & 2 & 143 \\
\cline { 2 - 7 } & $\%$ & 28,7 & 62,2 & 7,69 & 1,4 & $100 \%$ \\
\hline 7 & mendengarkan efektif & Frekuensi & 67 & 71 & 5 & 0 & 143 \\
\cline { 2 - 7 } & $\%$ & 46,9 & 49,7 & 3,5 & 0 & $100 \%$ \\
\hline Rata-rata & Frekuensi & 59 & 76,4 & 7 & 0,57 & 143 \\
\cline { 2 - 7 } & $\%$ & 41,3 & 53,4 & 4,9 & 0,4 & $100 \%$ \\
\hline
\end{tabular}

Berdasarkan hasil skala psikologis kecerdasan interpersonal siswa ini, memperkuat asumsi bahwa kecerdasan interpersonal siswa di SMA Negeri 5 Bau-bau, secara umum masih berada pada kategori sedang dan perlu untuk ditingkatkan sesuai dengan permasalahan yang selama ini terjadi di lapangan, bahwa siswa masih berbicara kasar pada temannya, masih ada siswa yang memaki temannya, masih ada siswa yang melawan guru, memaki guru, cara berkomunikasi yang kurang sopan serta belum mengetahui bagaimana harus menempatkan dirinya di lingkungan sosial sebagai seorang pelajar di sekolah maupun di luar sekolah.

Dari pemaparan di atas perlu upaya untuk menikatkan Kecerdasan interpersonal karena Kecerdasan interpersonal merupakan hal yang sangat penting bagi kehidupan individu sebab dengan kecerdasan interpersonal yang tinggi individu tidak terlalu mengalami kesulitan dalam membina hubungan dengan orang lain, baik dengan orang yang baru dikenal maupun dengan teman lama, sebaliknya individu yang memiliki kecerdasan interpersonal yang rendah akan mengalami kesulitan dalam membina hubungan sosial dengan orang lain di lingkungannya. Hal ini senada dengan apa yang dikatakan oleh Safaria (2005: 23), kecerdasan interpersonal atau bisa juga dikatakan kecerdasan sosial diartikan sebagai kemampuan dan keterampilan seseorang dalam menciptakan relasi sosialnya sehingga kedua belah pihak berada dalam situasi menang-menang atau saling menguntungkan. Lalu Goleman (2006: 166), melanjutkan bahwa individu dengan tingkat kecerdasan interpersonal tinggi tidak terlalu mengalami kesulitan dalam membina hubungan dengan orang lain, baik dengan orang yang baru dikenal maupun dengan teman lama.

Model bimbingan kelompok berbasis nilai-nilai budaya Buton, yang dikembangkan dalam penelitian ini dirumuskan dari kerangka kerja dengan desain model hipotetik berlandaskan kondisi dilapangan, teori bimbingan kelompok secara umum, nilai-nilai budaya Buton dan kondisi kecerdasan interpersonal siswa di SMA Negeri Bau-bau. model bimbingan kelompok berbasis nilai-nilai budaya Buton untuk meningkatkan kecerdasan interpersonal siswa yang terdiri dari delapan komponen yaitu 1) rasional, 2) visi dan misi, 3) tujuan, 4) isi bimbingan kelompok, 5) dukungan sistem bimbingan kelompok, 6) Tahap-tahap 
bimbingan kelompok berbasis nilai-nilai budaya Buton, 7) materi bimbingan kelompok berbasis nilai-nilai budaya Buton. dan 8) jenis permainan dalam bimbingan kelompok. Model ini telah divalidasi oleh dua ahli bimbingan dan konseling dan dua ahli budaya Buton serta sembilan praktisi guru bimbingan dan konseling di SMA Negeri Bau-bau. Hasil uji kelayakan menunjukkan bahwa model yang dirancang layak untuk diimplementasikan (model selengkapnya terlampir).

Bimbingan kelompok berbasis nilai-nilai budaya Buton dapat digunakan untuk meningkatkan kecerdasan interpersonal siswa, dilakukan dalam suasana bimbingan kelompok agar siswa lebih mudah memahami pembahasan topik dan nilainilai budaya Buton untuk mencapai kecerdasan interpersonal, melalui tahapan dalam bimbingan kelompok, yaitu (1) tahap Pembentukan (2) Tahap Peralihan (3) Tahap Kegiatan dan (4) Tahap Pengakhiran. Nilai-nilai budaya Buton akan dimasukkan sejak tahap pembukaan bimbingan kelompok sampai tahap kegiatan. Pada tahap pembukaan nilai-nilai budaya Buton hanya berfungsi sebagai pengantar agar saling menghargai dalam pelaksanaan bimbingan kelompok seperti nilai adatina pogau te adatina pomingku (etika berbicara dan etika berprilaku) dan nilai pobinci-binciki kuli, ("saling mencubit kulit" yang bermakna: "pandai memahami perasaan orang lain), pada tahap kegiatan dalam bimbingan kelompok pemimpin kelompok akan membahas topik yang berkaitan dengan kecerdasan interpersonal dan mengintenalisasikan nilai-nilai budaya Buton yang berkaitan dengan topik yang dibahas agar dapat meningkatkan kecerdasan interpersonal siswa adapun topik dan nilai-nilai budaya Buton yang akan dibahas yaitu: 1) Kesadaran diri dapat ditingkatkan dengan pobinci-binciki kuli ("saling mencubit kulit" yang bermakna: "pandai memahami perasaan orang lain), 2) Pemahaman situasi sosial dan etika sosial dapat ditingkatkan dengan pomae-maeka (yaitu takut kepada Allah untuk menyakiti orang lain karena mereka juga makhluk Allah seperti kita, saling segan dan menjaga kehormatan sesama atau menjunjung tinggi hak asazi manusia dan supremasi hukum/adat/kontrak sosial), dan disisipkan dengan adatina pogau-te adatina pomingku. 3) Keterampilan memecahkan masalah dapat ditingkatkan dengan paangkaangkataka, (saling mengangkat derajat sesama atau membangun kepedulian sosial) 4) Sikap empati dapat ditingkatkan dengan nilai pomamasiaka (saling menyayangi dalam suatu ikatan yang kokoh dan tulus), dan nilai pobinci-binciki kuli, 5) Sikap prososial dapat ditingkatkan dengan nilai bholimo karo sumanamo lipu (mengutamakan kepentingan sosial diatas kepentingan pribadi) 6) Komunikasi efektif dapat ditingkatkan dengan popia-piara (saling menjaga perasaan dan mengembangkan sikap saling menghargai) dan disisipkan dengan adatina pogau-te adatina pomingku (adat berbicara dan berprilaku). Mendengarkan efektif dapat ditingkatkan dengan popia-piara (saling menjaga perasaan dan mengembangkan sikap saling menghargai) dan disisipkan dengan adatina pogau-te adatina pomingku artinya etika berbicara dan etika berprilaku.

Grafik 1.Perbandingan skor pre test dan post test siswa secara keseluruhan 


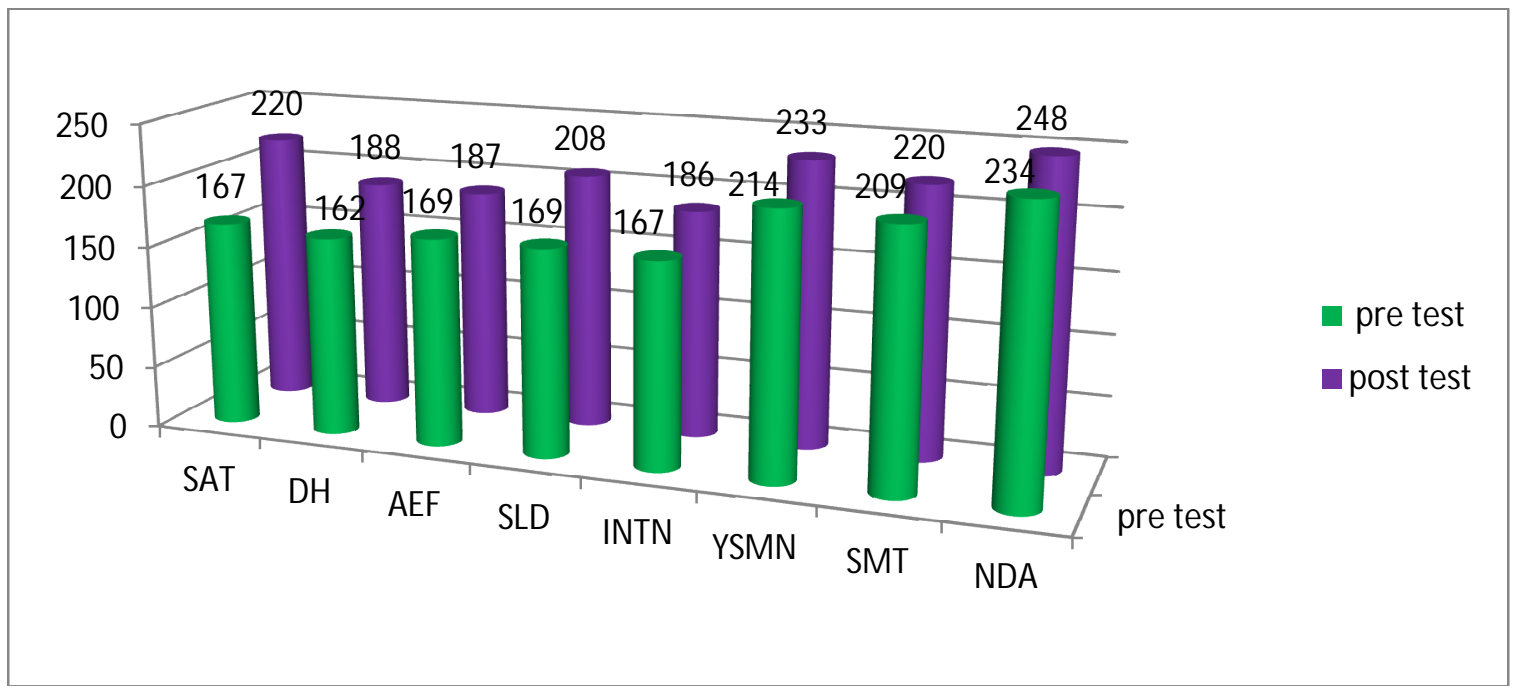

Berdasarkan Garfik tersebut, terlihat bahwa terjadi kenaikan skor kecerdasan interpersonal siswa setelah diberikan layanan bimbingan kelompok berbasis nilai-nilai budaya Buton dibandingkan dengan skor kecerdasan interpersonal siswa sebelum diberikan layanan bimbingan kelompok berbasis nilai-nilai budaya Buton. Secara keseluruhan, skor kecerdasan interpersonal siswa mengalami kenaikan 199 poin atau sebesar $11,77 \%$. Peningkatan kecerdasan interpersonal siswa perindikator setelah diberikan bimbingan kelompok berbasis nilai-nilai budaya Buton selengkapnya dapat dilihat pada paparan secara rinci sebagai berikut: pada aspek sikap empati mengalami kenaikan sebesar 16,27, pada aspek sikap prososial mengalami kenaikan sebesar 10,50\%. pada aspek kesadaran diri mengalami kenaikan sebesar $10,07 \%$ pada aspek pemahaman situasi sosial dan etika sosial mengalami kenaikan sebesar $11,76 \%$, pada aspek Keterampilan Memecahkan Masalah mengalami kenaikan sebesar 16,26\%. pada aspek komunikasi efektif mengalami kenaikan sebesar 10,87\%. pada aspek mendengarkan efektif mengalami kenaikan sebesar 9,83\%. berdasarkan hasil pemaparan diatas terlihat bahwa yang mengalami peningkatan yang paling tinggi pada aspek sikap empati dan pada aspek keterampilan memecahkan masalah.

Peningkatan skor kecerdasan interpersonal siswa tidak lepas dari proses yang dialami oleh siswa, berupa dinamika kelompok yang terjadi dari setiap pertemuan dalam penyelenggaraan bimbingan kelompok berbasis nilai-nilai budaya Buton. Selain itu, kesediaan siswa untuk mengaplikasikan nilai-nilai budaya Buton, dalam kehidupan mereka seharihari memiliki kontribusi dalam peningkatan skor kecerdasan interpersonal tersebut.

Pentingnya penginternalisasian nilai-nilai budaya Buton dalam bimbingan kelompok untuk mengintervensi kecerdasan interpersonal siswa didasari oleh asumsi bahwa nilai-nilai budaya menjadi salah satu tolak ukur untuk menyatakan baik atau buruknya perilaku individu di dalam sebuah lingkungan sosial. Nilainilai budaya yang menjadi pedoman umum dari kerangka tindakan. Juga menjadi pusat orientasi berbagai aturan yang diperlukan dalam rangka interaksi antar individu, baik di lingkungan 
pergaulan keluarga, maupun di tengahtengah masyarakat. Kenyataan ini menunjukkan bahwa latar belakang Nilai-nilai budaya lokal memiliki pengaruh terhadap cara berinteraksi individu dalam kehidupannya seharihari. Hal ini sejalan dengan pandangan Liliweri (2013:137) mengatakan bahwa setiap kebudayaan harus memiliki nilainilai dasar yang merupakan pandangan hidup dan sistem kepercayaan dimana semua pengikutnya berkiblat. Nilai dasar itu membuat para pengikutnya untuk dapat menjadikan nilai budya sebagai tolak ukur dalam bertindak dan bersikap dan mengatur bagaimana cara mereka melihat keluar. Nilai dasar itu merupakan filosofi hidup atau pedoman hidup yang dijadikan sebagai penuntun dalam menjalani hidup sehari-hari.

Untuk menjawab hipotesis penelitian dilaukan uji efektifitas dengan membandingkan antara skor pre test dan skor post test menggunakan wilcoxon berbantuan perangkat lunak (software) SPSS 20.00 for Windows. Paparan lebih rinci terhadap uji signifikansi dengan menggunakan Wilcoxon dapat dilihat pada tabel 2. Berikut:

Test Statistics ${ }^{\text {a }}$

\begin{tabular}{lr}
\hline & $\begin{array}{c}\text { Evaluasi akhir - } \\
\text { Evaluasi awal }\end{array}$ \\
\hline $\mathrm{Z}$ & $-2.524^{\mathrm{b}}$ \\
$\begin{array}{c}\text { Asymp. Sig. (2- } \\
\text { tailed) }\end{array}$ & .012 \\
\hline
\end{tabular}

a. Wilcoxon Signed Ranks Test

b. Based on negative ranks.

Hasil uji skala kecerdasan interpersonal pada skor total diperoleh nilai probabilitas dibawah 0,05 yaitu $(0,012<0,05)$, artinya ada perubahan peningkatan antara sebelum dan sesudah diberikan layanan bimbingan kelompok berbasis nilai-nilai budaya
Buton, sehingga dapat dikatakan bahwa bimbingan kelompok berbasis nilai-nilai budaya Buton terbukti efektif untuk meningkatkan kecerdasan interpersonal siswa.

Model bimbingan kelompok berbasis nilai-nilai budaya Buton berangkat dari hasil analisis kebutuhan (need assesment) sehingga relevan dengan kebutuhan di lapangan, yang menunjukkan perlunya upaya strategis dalam memberikan layanan yang berkualitas serta perlunya intervensi nilai-nilai budaya Buton terhadap siswa yang terindikasi memiliki kecerdasan interpersonal rendah.

Pengalaman peneliti sebagai pemimpin kelompok dalam kegiatan bimbingan kelompok dengan memanfaatkan nilai-nilai budaya Buton untuk meningkatkan kecerdasan interpersonal siswa, ditemukan bahwa prosedur pelaksanaan bimbingan kelompok berbasis nilai-nilai budaya Buton untuk meningkatkan kecerdasan interpersonal siswa, berjalan lancar dan dapat diterima dengan baik oleh anggota kelompok. Anggota kelompok aktif dalam mengemukakan pendapat tentang topik yang dikaitkan dengan nilai-nilai budaya Buton, karena nilainilai itu sudah pernah didengar tetapi tidak sampai diterapkan pada sikap sehari-hari mereka, olehnya itu model bimbingan kelompok berbasis nilai-nilai budaya Buton dapat disambut dengan baik oleh siswa yang berbudaya Buton sehingga dapat meningkatkan kecerdasan interpersonal siswa di SMA Negeri Bau-bau

\section{KESIMPULAN}

Pelaksanaan bimbingan kelompok di SMA Negeri Bau-bau telah dilaksanakan oleh guru bimbingan dan konseling sesuai dengan tahapan 
bimbingan kolompok yang umum. Namun belum menggunakan pendekatan budaya setempat dan belum membahas topik-topik yang berkaitan dengan kecerdasan interpersonal secara spesifik, sehingga efektifitas layanan bimbingan kelompok tidak tercapai secara optimal. Berdasarkan hasil penyeberan instrumen skala psikologis kecerdasan interpersonal siswa, diketahui bahwa hasil penelitian tentang kecerdasan interpersonal siswa di SMA Negeri 5 Bau-bau, pada umumnya siswa berada pada kategori sedang. Data ini memperkuat asumsi bahwa kecerdasan interpersonal siswa di SMA Negeri 5 Bau-bau, perlu untuk ditingkatkan. Telah dihasilkan model bimbingan kelompok berbasis nilai-nilai budaya Buton untuk meningkatkan kecerdasan interpersonal siswa yang terdiri dari delapan komponen yaitu 1) rasional, 2) visi dan misi, 3) tujuan, 4) isi bimbingan kelompok, 5) dukungan sistem bimbingan kelompok, 6) Tahaptahap bimbingan kelompok berbasis nilai-nilai budaya Buton, 7) materi bimbingan kelompok berbasis nilai-nilai budaya Buton. dan 8) jenis permainan dalam bimbingan kelompok. Hasil uji model bimbingan kelompok berbasis nilai-nilai budaya Buton terbukti efektif untuk meningkatkan kecerdasan interpersonal siswa

\section{DAFTAR PUSTAKA}

Arikunto, Suharsimi. 2006. Manajemen Penelitian. Jakarta : Rineka Cipta

Goleman, D. 2006. Emotional Intelligence. Jakarta: Gramedia Pustaka Utama

Hurlock, E.B. 2009. Psikologi
Perkembangan.
Erlangga.

Liliweri, Alo. 2013. Dasar-dasar Komunikasi Antarbudaya. Yogyakarta: Pustaka Pelajar

Romlah, Tatiek. 2006. Teori dan Praktik Bimbingan Kelompok. Malang; UM Press.
Safaria, T. 2005 Interpersonal Intelligence:Metode
Pengembangan Kecerdasan
Interpersonal
Anak.
Yogyakarta: Amara Books
Samsudi. 2009. Desain Penelitian Pendidikan. Semarang: UNNES PRESS

Tilaar, HAR. 2004. Paradigma Baru Pendidikan Indonesia. Jakarta: Rineka Cipta. 